\title{
ANALISIS KOMPARATIF PENDAPATAN ANTARA USAHA BECAK KAYUH DAN BECAK MOTOR DI SEKITAR PLAZA LAMONGAN
}

\author{
*(Nasrotul Adhimah ${ }^{1}$, Ruswaji $^{2}$, Pudiastiono $^{3}$ \\ Prodi Manajemen, Fakultas Ekonomi, Universitas Islam Lamongan \\ $\mathrm{Jl}$. Veteran No.53A Lamongan \\ Telp. ( 0322 ) 324706, Faks. ( 0322 ) 324706 \\ Email :jpim@unisla.ac.id
}

\begin{abstract}
ABSTRAK
Telah dilakukan penelitian tentang analisis komparatif pendapatan antara usaha becak kayuh dan becak motor di sekitar Plaza lamongan. Penelitian ini bertujuan untuk mengetahui adanya perbedaan yang signifikan dan mengetahui pendapatan mana yang lebih besar antara usaha becak kayuh dengan usaha becak motor di sekitar Plaza Lamongan. Penelitian ini menggunakan metode deskriptif komparatif dengan pendekatan kuantitatif antara usaha becak kayuh $\left(X_{1}\right)$ dan usaha becak motor $\left(X_{2}\right)$. Sampel diambil dengan menggunakan teknik simple random sampling dan wawancara terhadap 20 responden usaha becak yaitu 10 usaha becak kayuh dan 10 usaha becak motor. Analisis dilakukan dengan cara mencari pendapatan bersih dan kemudian dilakukan uji komparatif menggunakan independent sample t-test dengan nilai signifikan 0.05. Uji komparatif telah dilakukan dan dihasilkan $t_{\text {hitung }}$ lebih besar daripada $t_{\text {tabel }}(2.968>1.734)$, sehingga dapat diketahui bahwa terdapat perbedaan yang signifikan antara pendapatan usaha becak kayuh dan usaha becak motor. Uji komparatif juga menunjukkan bahwa pendapatan bersih rata-rata per tahun usaha becak kayuh yaitu sebesar Rp. 7,250,500.00 lebih besar dibandingkan dengan usaha becak motor yaitu sebesar Rp. 5,423,000.00.
\end{abstract}

Kata kunci : pendapatan, becak kayuh, becak motor.

\section{PENDAHULUAN}

Lamongan merupakan kabupaten dengan perekonomian yang bertumpu pada kegiatan pertanian dan perdagangan sehingga diperlukan sarana transportasi baik tradisional maupun modern. Sebagian besar masyarakat mengandalkan becak sebagai alat transportasi baik itu untuk tujuan pengangkutan barang mapun mobilitas masyarakat dari suatu tempat ke tempat lain. Terdapat dua jenis becak yang tersebar di Lamongan, yaitu becak kayuh dan becak motor. Sebagian besar keberadaan kedua jenis becak tersebut berada di sekitar Lamongan Plaza. Jika diperhatikan keberadaannya, sebagian besar baik becak kayuh maupun becak motor tetap bertahan sebagai profesi masyarakat Lamongan. Dalam keseharian antara kedua jenis becak tersebut terjadi persaingan. Karena perbedaan tingkat mobilitas antara keduanya mengakibatkan perbedaan penghasilan. Oleh karena itu, penulis tertarik untuk melakukan penelitian tentang perbedaan penghasilan antara kedua jenis becak tersebut dengan judul "Analisis Komparatif Pendapatan Antara Usaha Becak Kayuh dengan 
Usaha Becak Motor di Sekitar Plaza Lamongan".

Penelitian ini bertujuan untuk mengetahui adanya perbedaan pendapatan dan untuk mengetahui mana yang lebih besar pendapatan antara usaha becak kayuh dengan usaha becak motor di sekitar Plaza Lamongan.

\section{Hipotesis}

1. Diduga ada perbedaan yang signifikan antara pendapatan usaha becak kayuh dengan pendapatan usaha becak motor di sekitar Plaza Lamongan.

2. Diduga pendapatan usaha becak kayuh lebih besar daripada pendapatan usaha becak motor di sekitar Plaza Lamongan.

\section{TINJAUAN PUSTAKA}

Marlina Perdana Putri (2011) melakukan penelitian dengan judul "Analisis komparatif usaha tani tumpangsari jagung dan kacang tanah dengan monokultur jagung di Kabupaten Wonogiri". Metode dasar penelitian adalah metode deskriptif analitik dan pelaksanaanya dengan teknik survei. Teknik pengambilan petani sampel dengan menggunakan metode pengambilan simple random sampling dengan cara undian. Jenis data yang digunakan dalam penelitian ini adalah data primer dan sekunder. Metode analisis yang digunakan antara lain pendapatan dan efesiensi menggunakan uji t. Hasil penelitian menunjukkan bahwa pendapatan usaha tani tumpangsari jagung-kacang tanah (Rp. 8.449.479,00/Ha) lebih besar daripada pendapatan usaha tani monokultur jagung yang besarnya (Rp.5.893.727,00/Ha). Hasil uji t antara pendapatan usaha tani monokultur jagung dan tumpangsari jagung-kacang tanah menunjukkan bahwa thitung sebesar 6,264, berarti usaha tani tumpang sari jagung - kacang tanah memberikan pendapatan yang lebih tinggi jika dibandingkan dengan usaha tani monokultur jagung. Nilai R/C Ratio pada usaha tani monokultur jagung besarnya 1,70, sedangkan R/C Ratio pada usaha tani tumpangsari jagung-kacang tanah 1,90. Hasil uji t antara efesiensi usaha tani monokultur jagung dan tumpangsari jagung-kacang tanah menunjukkan bahwa thitung besarnya 4,672. Hal ini dapat diartikan bahwa usaha tani tumpangsari jagung-kacang tanah lebih efisien untuk dikembangkan daripada usaha tani monokultur jagung.

Kaharuddin pada tahun 2012 dengan judul skripsi “Analisis Perbandingan 
Produksi dan Pendapatan Petani Padi Pengguna Paket Teknologi Pupuk Berimbang dan Pupuk tidak Berimbang di Kabupaten Takalar". Variabel yang digunakan adalah pupuk berimbang dan pupuk tidak berimbang. Penelitian ini bertujuan untuk mengetahui perbedaan produksi dan pendapatan petani yang menggunakan paket teknologi pupuk berimbang dan pupuk tidak berimbang. Alat analisis yang digunakan analisis $\mathrm{R} / \mathrm{C}$ ratio untuk mengetahui layak atau tidaknya suatu teknologi untuk diterapkan. Hasil penelitian didapatkan usaha tani padi yang menggunakan pupuk berimbang dan pupuk tidak berimbang perlu ditingkatkan penggunaannya karena nilai $\mathrm{R} / \mathrm{C}$ ratio $>1$, produksi dan pendapatan petani yang menggunakan paket pemupukan berimbang mengalami peningkatan dibandingkan dengan yang tidak menggunakan paket pemupukan berimbang yang ditandai dengan nilai $\mathrm{R} / \mathrm{C}$ ratio yang diperoleh penggunaan teknologi pupuk berimbang yang lebih tinggi yaitu sebesar 2,26 dibandingkan dengan $\mathrm{R} / \mathrm{C}$ ratio penggunaan teknologi tanpa pupuk berimbang sebesar 1,73.

Siti Yulianty Chansa Arfah (2013) dengan judul skripsi “Analisis komparatif pendapatan usaha tani sawah sistem tabela dan sistem tapin". Variabel yang digunakan adalah sistem tabela (X1) dan sistem tapin (X2). Penelitian ini untuk mengetahui perbedaan pendapatan usaha tani yang menggunakan sistem tabela dan sistem tapin. Alat analisis yang digunakan analisis $\mathrm{R} / \mathrm{C}$ ratio untuk mengetahui layak atau tidaknya suatu sistem untuk diterapkan. Perbedaan penelitian yang terdahulu dengan penelitian sekarang adalah tempat dan tahun penelitiannya serta variabel yang akan diteliti. Persamaan penelitian yang terdahulu dengan penelitian sekarang adalah samasama penelitian komparatif untuk mencari besarnya pendapatan. Hasil penelitian didapatkan usaha tani sistem tabela dan tapin layak diusahkan karena nilai R/C > 1. Nilai t-hitung sebesar $-3,223<\mathrm{t}$-tabel pada $\alpha 5 \%(1,701)$ dan $<\alpha 1 \%(2,763)$ yang berarti Ho tidak dapat ditolak, dan H1 tidak teruji kebenarannya yang berarti pendapatan usaha tani padi sawah sistem tapin lebih besar dari pada sistem tabela.

Nur Anifah tahun 2015 "Analisis komparatif penggunaan pupuk organik dengan pupuk anorganik terhadap hasil usaha tani pada petani padi Desa Mentaras Kecamatan Dukun Kabupaten Gresik". Variabel dalam penelitian ini adalah variabel usaha tani menggunakan 
pupuk organik (X1), dan hasil usaha tani menggunakan pupuk anorganik (X2). Penelitian ini mengambil sebanyak 32 orang petani dengan rincian 16 petani menggunakan pupuk organik dan 16 petani menggunakan pupuk anorganik yang lahannya siap panen. Dari hasil penelitian dapat disimpulkan pupuk organik menghasilkan pendapatan usaha tani yang lebih besar yaitu rata-rata sebesar Rp.12.041.563, sedangkan petani yang menggunakan pupuk anorganik menghasilkan pendapatan usaha tani sebesar Rp.10.276.094.

\section{METODE PENELITIAN}

\section{Waktu dan Lokasi Penelitian}

Waktu yang digunakan untuk melakukan penelitian ini adalah pada bulan November 2017 sampai Mei 2018. Lokasi penelitian ini di kota Lamongan tepatnya di pangkalan becak sekitar Plaza Lamongan.

\section{Jenis Penelitian}

Metode yang digunakan dalam penelitian ini adalah metode deskriptif komparatif pendekatan kuantitatif, yaitu memberikan gambaran tentang pendapatan masing-masing usaha becak kayuh dan usaha becak motor, kemudian dilakukan pembandingan atas pendapatan kedua usaha becak tersebut. Selanjutnya dilakukan penarikan hubungan seberapa signifikan pendapatan antara kedua usaha becak tersebut.

\section{Teknik Penarikan Sampel}

Teknik pengambilan data dalam penelitian ini menggunakan area sampling adalah teknik sampling yang dilakukan dengan cara mengambil wakil dari setiap daerah/wilayah geografis yang ada, karena menurut pendapat peneliti merekalah yaitu individu-individu yang dipilih itu mengerti tentang populasi. Sedangkan yang menjadi objek dalam penelitian ini adalah pendapatan usaha becak kayuh dan usaha becak motor.

\section{Populasi}

Jumlah usaha becak yang tersebar di sekitar Plaza Lamongan tidak lebih dari 100 orang baik becak kayuh maupun becak motor, maka peneliti mengumpulkan data sebanyak 20 responden usaha becak.

\section{Sampel}

Sampel ditentukan berdasarkan jumlah populasi, maka peneliti menentukan sampel dari populasi 20 orang usaha becak sekitar Plaza 
Lamongan yaitu 10 usaha becak kayuh dan 10 usaha becak motor.

\section{Teknik Sampling}

Penelitian ini menggunakan teknik simple random sampling yaitu sampel diambil secara acak dari keseluruhan usaha becak.

\section{Metode Pengumpulan Data}

Jika dilihat dari sumber datanya maka pengumpulan data dapat menggunkan sumber data primer dan data sekunder. Adapun metode yang digunakan penulis dalam proses pengumpulan data adalah:

\section{Sumber Data}

Terdapat 2 jenis sumber data yang digunakan dalam penelitian ini, yaitu:

\section{Data primer}

Pengumpulan data primer dalam penelitian ini melalui cara melakukan wawancara secara langsung pada usaha becak.

2. Data sekunder

Pengumpulan data sekunder dalam penelitian ini dilakukan melalui studi kepustakaan dengan tujuan untuk memperoleh literatur pada penelitian terdahulu dan teori penunjang. Baik melalui buku, laporan ilmiah, artikel, ataupun surat kabar.

\section{Teknik Pengambilan Data}

Teknik pengambilan data pada penelitian ini dilakukan dengan cara wawarancara langsung kepada usaha becak, baik usaha becak kayuh maupun usaha becak motor.

\section{Operasional Variabel}

Variabel yang digunakan dalam penelitian ini dibagi menjadi 2 variabel, yaitu $\mathrm{X}_{1}$ yang mewakili pendapatan usaha becak motor dan $\mathrm{X}_{2}$ yang mewakili pendapatan usaha becak motor.

\section{Metode Analisis Data}

\section{Analisa deskriptif}

Analisa ini dengan cara membuat diskriptif, gambaran, atau lukisan secara sistematis, faktual dan akurat mengenai fakta-fakta, sifat-sifat serta hubungan antar fenomena yang diselidiki.

Analisis pendapatan usaha becak yaitu jumlah upah yang diterima sebagai imbalan jasa dengan satuan perhitungan bulanan. Perhitungan pendapatan bersih:

Pendapatan bersih = pendapatan kotor - biaya operasional 
2. Uji hipotesis

Uji hipotesis dalam penelitian ini menggunakan independent sample $t$ test, yaitu dilakukan dengan cara menentukan pendapatan rata-rata per tahun usaha becak kayuh dan usaha becak motor. Selanjutnya dilakukan pembandingan antara kedua pendapatan usaha becak tersebut dengan tujuan untuk mengetahui seberapa signifikan perbedaan antara kedua pendapatan becak tersebut menggunakan persamaan berikut:

$$
t=\frac{\bar{X}_{A}-\bar{X}_{B}}{S g a b \sqrt{\frac{1}{n_{A}}-\frac{1}{n_{B}}}}
$$

$\mathrm{t}=$ mencari nilai thitung

Dimana :

$S g a b=\sqrt{\frac{\left(n_{A}-1\right) S_{A}^{2}+\left(n_{B}-1\right) S_{B}^{2}}{n_{A}+n_{B}-2}}$

Keterangan :

$\bar{X}_{A}=$ rata-rata usaha becak kayuh

$\bar{X}_{B}=$ rata-rata usaha becak motor

$S_{A}^{1}=$ varian kelompok usaha becak

kayuh

$S_{B}^{2}=$ varian kelompok usaha becak

motor

$n_{A}=$ banyaknya sampel kelompok

usaha becak kayuh
$n_{B}=$ banyaknya sampel kelompok usaha becak motor $S g a b=$ simpangan baku gabungan

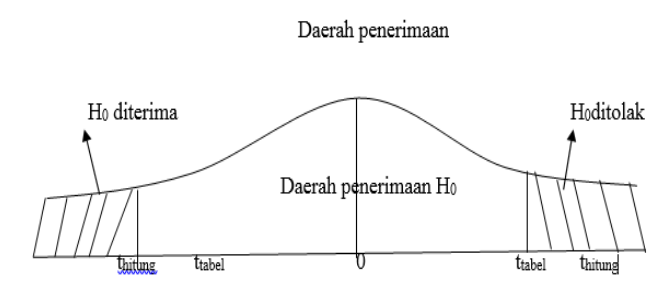

Gambar 3.1 Daerah Penerimaan dan Penolakan (Uji t)

Kesimpulan pengujian dilakukan dengan membandingkan antara thitung dengan ttabel sebagai berikut:

- Bila $t_{\text {hitung }}<t_{\text {tabel, }}$ maka $\mathrm{H}_{0}$ diterima dan H1 ditolak yang berarti tidak ada perbedaan pendapatan usaha becak menggunakan becak kayuh dengan pendapatan usaha becak menggunakan becak motor.

- Bila $t_{\text {hitung }}>\mathrm{t}_{\text {tabel }}$, maka $\mathrm{H}_{0}$ ditolak dan H1 diterima berarti ada perbedaan pendapatan usaha becak menggunakan becak kayuh dengan pendapatan usaha becak menggunakan becak motor.

\section{HASIL DAN PEMBAHASAN}

Usaha becak yang menggunakan becak kayuh menghasilkan pendapatan bersih usaha becak yang lebih besar 
yaitu rata-rata sebesar Rp. 72.505.000.

Sedangkan usaha becak yang menggunakan becak motor menghasilkan pendapatan bersih usaha becak sebesar Rp. 54.230.000. Hal ini diakibatkan karena biaya operasionalnya becak motor yang lebih tinggi dibandingkan dengan usaha becak kayuh.

Varian Usaha Becak Kayuh

$$
\begin{aligned}
\mathrm{S}_{1}^{2} & =\frac{\sum(X 1-\bar{X} 1)^{2}}{n-1} \\
& =\frac{23,120,123}{10-1} \\
& =\frac{23,120,123}{9} \\
& =2.568 .903
\end{aligned}
$$

Varian Usaha Becak Motor

$$
\begin{aligned}
S_{2}^{2} & =\frac{\sum(X 2-\bar{X} 2)^{2}}{n-1} \\
& =\frac{24,980,410}{10-1} \\
& =\frac{24,980,410}{9} \\
& =2.775 .601
\end{aligned}
$$

Menghitung Varian gabungan (Sgab)

$S g a b=\sqrt{\frac{(n a-1) \cdot S 1^{2}+(n b-1) \cdot S 2^{2}}{n a+n b-2}}$

$\sqrt{\frac{(10-1) \cdot 2,568,903+(10-1) \cdot 2,775,601}{10+10-2}}$

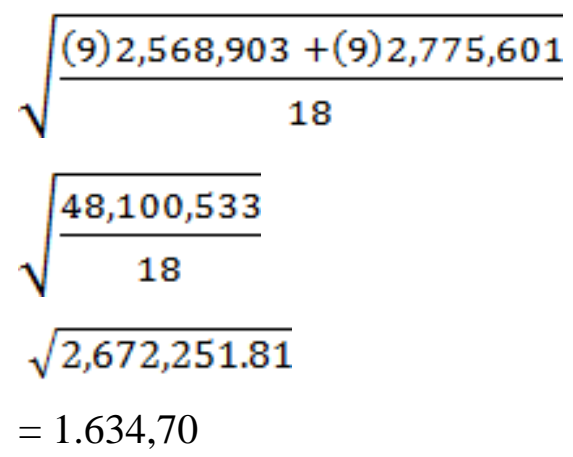

Menghitung uji independent sample ttest

$$
\begin{aligned}
\mathrm{t} & =\frac{\bar{X} 1-\bar{X} 2}{\operatorname{Sgab} \sqrt{\frac{1}{n a}+\frac{1}{n b}}} \\
& =\frac{7,250.5-5,423.0}{1,634.70 \sqrt{\frac{1}{10}+\frac{1}{10}}} \\
& =\frac{1827.5}{1,634.70 \sqrt{0.2}} \\
& =\frac{1827.5}{(1,634.70) \cdot(0.447)} \\
& =\frac{1827.5}{730.710} \\
& =2,500
\end{aligned}
$$

Dalam pengujian hipotesis, derajat bebas ditentukan dengan rumus $n-k$. Dimana $\mathrm{n}$ = banyak observasi , sedangkan $\mathrm{k}$ = banyaknya variabel. Sehingga dapat diketahui bahwa $\mathrm{df}=$ 20-2, maka df $=18$, dengan nilai $\alpha=$ $5 \%(0,05)$. Jika df $=18$ maka nilai $t_{\text {tabel }}$ $=2,500$.

Berdasarkan hasil analisis menunjukkan nilai $t_{\text {hitung }}$ sebesar 2,500 
dengan nilai signifikan 0,05 tampak bahwa nilai $t_{\text {hitung }}$ lebih besar dari $t_{\text {tabel }}$ $1,734\left(t_{\text {hitung }}>t_{\text {tabel }}\right)=(2,500>1,734)$. Maka menghasilkan kesimpulan $\mathrm{H}_{0}$ ditolak dan $\mathrm{H}_{1}$ diterima berarti ada perbedaan yang signifikan antara pendapatan bersih usaha becak menggunakan becak kayuh dengan pendapatan bersih usaha becak menggunakan becak motor.

\section{PENUTUP}

\section{Kesimpulan}

- Dari hasil uji analisis data menggunakan independent sample t-test didapatkan perbedaan yang signifikan antara pendapatan bersih usaha becak kayuh dengan usaha becak motor pada tahun 2017 di sekitar Plaza Lamongan. Hal ini ditunjukkan mempunyai $t_{\text {hitung }}$ 2,500, sehingga nilai $t_{\text {hitung }}>t_{\text {tabel }}$ yaitu $2,500>1,734$ dengan nilai signifikansi $\alpha<0,05$.

- Usaha becak kayuh menghasilkan pendapatan usaha becak yang lebih besar yaitu rata-rata sebesar Rp. 72.505.000. Sedangkan usaha becak yang menggunakan becak motor menghasilkan pendapatan usaha becak motor sebesar Rp. 54.230 .000 .

\section{DAFTAR PUSTAKA}

Arikunto, Suharsimi. 2006. Prosedur Penelitian. Penerbit Rineka Cipta, Jakarta

Arikunto, Suharsimi. 2010. Prosedur Penelitian Suatu Pendekatan Praktik. Rineka Cipta, Jakarta

Darmawan. 2012. Akuntansi Itu ternyata Logis dan Mudah. Raja Buku, Bandung

Harahap, Sofyan Syafri. 2011. Teori Akuntansi. Raja Grafindo Persada, Jakarta

Herliswanny. 2014. Sikap Budaya Antri Masyarakat. Cultural, Yogyakarta

Jusup, Al Haryono. 2011. Dasar-dasar Akuntansi. YKPN, Yogyakarta

Jhingan, 2013, Ekonomi Pembangunan dan Perencaan. Rajawali Pers, Jakarta

Khairandy, Ridwan. 2007. Dari Shareholder ke Stakeholder, Dari Etika Bisnis ke Norma Hukum. Badan Korporasi UII Press, Yogyakarta

Kotler, Philip. 2008. Manajemen Pemasaran. Erlangga, Jakarta

Mulia. 2013. Teori Ekonomi Makro: Pendekatan pada Ekonomi Indonesia. Djambatan, Jakarta

Miro, Fidel Simarmata Lemeda. 2012. Pengantar Sistem Transportasi. Erlangga, Jakarta

Morlok, Edward. 2004. Pengantar Teknik dan Perencanaan Transportasi. Erlangga, Jakarta Nasution. 2008. Manajemen Transportasi. Bumi Perkasa, Jakarta 
Niswonger, Rollin. 2009. Prinsipprinsip Akuntansi. Erlangga, Jakarta

Nordhaus, Samuelson. 2013. Ilmu Mikro Ekonomi. Global Media Edukasi, Jakarta

Nasution, Arman Hakim. 2003. Perencanaan dan Pengendalian Persedian Transportasi. Rosda, Bandung

Reksoprayitno. 2012. Sistem Ekonomi dan Demokrasi Ekonomi. Bina Grafika, Jakarta

Salim, Abbas. 2013. Manajemen Transportasi. Raja Grafindo Perdasa, Jakarta

Soekartawi. 2004. Faktor-faktor Produksi. Salemba Empat, Jakarta

Soemarso. 2004. Akuntansi Suatu Pengantar. Salemba Empat, Jakarta

Sunuharjo. 2009. Kemiskinan dan Kebutuhan Pokok. Yayasan Ilmu Sosial, Jakarata

Sukirno, $\quad 2002$. Makroekonomi. Raja Grafindo Persada, Jakarta

Sugiyono. 2014. Metode Penelitian Kuantitatif Kualitatif dan $R \& D$, Penerbit Alfabeta, Bandung

Sugiyono. 2014. Metode Penelitian Bisnis. Alfabeta, Bandung

Sugiyono. 2015. Metode Penelitian Pendidikan Pendekatan Kuantitatif dan Kualitatif dan $R \& D$. Alfabeta, Jakarta

Suparyanto, Yudi Sumadi. 2014. Wawasan Nusantara. Cempaka Putih, Klaten

Sutinah. 2013. Berbagai Alternatif Pendekatan. Kencana, Bogor

Sukestiyarno. 2014. prosedur penelitian suatu pendekatan praktik. Eka cipta, Jakarta
Swastha, Basu. 2013. Manjemen Penjualan. BPFE, Yogyakarta

Toweulu, Sudarman. 2011. Ekonomi Indonesia. Raja Grafindo, Jakarta

Winardi. 2007. Manajemen Konflik (Konflik Perubahan dan pengembangan). Mandar Maju, Makassar 